\title{
Mouse IPK: A Powerful Tool to Partially Characterize Renal Reperfusion and Preservation Injury
}

\author{
Susanne L. Lindell ${ }^{1,2}$, Natascha Williams ${ }^{1}$, Ilia Brusilovsky ${ }^{2}$ and Martin J. Mangino ${ }^{*}, 1,2,3,4$ \\ Department of Surgery ${ }^{1}$, Anesthesiology ${ }^{2}$, Emergency Medicine ${ }^{3}$, and Physiology and Biophysics ${ }^{4}$, Virginia \\ Commonwealth University, Medical College of Virginia Campus, Richmond, VA 232980, USA
}

\begin{abstract}
Main Problem: The molecular basis of renal preservation injury is not well understood. Since mouse kidney transplantation models are not useful in this setting, a mouse Isolated Perfused Kidney (IPK) model was developed to take advantage of mouse genetic design capabilities for testing complex biological hypothesis regarding mechanisms of preservation injury in transplanted kidneys.

Methods: Mouse kidneys were recovered, preserved, and reperfused in-vitro with an acellular physiological crystalloid buffer containing hypo-physiological oncotic pressure. Outcome variables were measured to predict preservation injury. These included perfusate flow, vascular resistance, $\mathrm{VO}_{2}$, urine output, GFR, proteinuria, LDH release, and edema. The model was tested by subjecting mouse kidneys to cold storage in University of Wisconsin (UW) solution for 24, 48, or 72 hours (time-dependent preservation injury), cold storage in Euro-Collins Solution (solution dependent preservation injury), and exposure to prior warm ischemia (DCD dependent preservation injury).

Results: The model accurately predicted the qualitative and quantitative changes in the readouts based on known responses to preservation injury in kidney transplants in large animals and humans.

Conclusion: The mouse IPK accurately predicts many of the variables associated with renal organ preservation injury in the very early phases of reperfusion and may provide an attractive model for studying the molecular basis of renal preservation injury.
\end{abstract}

Keywords: Kidney, ischemia, transplantation, methods, perfusion, function, murine, organ preservation, hypothermia.

\section{INTRODUCTION}

Renal transplantation continues to be the treatment of choice for patients with end stage renal failure. However, the high demand of organs has resulted in a dramatic organ shortages and a drive to expand the donor pool [1]. To this end, many deceased donors that were once considered unsuitable for donation are now being used. These include kidneys from donation after cardiac death (DCD), kidneys from older donors, and from donors with other risk factors. These practices have resulted in a decrease in graft function and survival, increase frequency of delayed graft function (DGF), and other complications such as acute rejection episodes and interstitial fibrosis and tubular atrophy, compared to organs retrieved from standard criteria donors [2-6]. More marginal and DCD donors suffers from additional warm ischemia. As a result, these organs have higher primary non function (PNF) and delayed graft function (DGF) rates and benefit from more aggressive preservation procedures such as perfusion preservation $[7,8]$. Maintaining organ viability after donation until transplantation is critically important for optimal graft function and survival. By accepting these extended criteria donors, improvements in organ preservation becomes a necessity and this occurs best by defining the mechanisms of injury.

*Address correspondence to this author at the Department of Surgery, Virginia Commonwealth University, Medical College of Virginia Campus, 1200 E. Broad St., 7108 West Hospital, Richmond, VA 23298, USA; Tel: 804-628-3226; Fax: 804-828-8300; E-mail: mjmangino@vcu.edu
The basic mechanisms of preservation (Ischemia) and reperfusion are poorly understood. Most modern day organ preservation solutions improve organ storage by decreasing oxygen demand with hypothermia while mitigating the deleterious effects of hypothermia on cells and tissues (cell swelling) [9-12]. However, the basic molecular mechanisms of preservation injury are not well understood and significant advancements in organ preservation injury have not been made since the advent of the University of Wisconsin (UW) flush and perfusion solutions over 20 years ago. Studies to dissect out molecular mechanisms of preservation injury may utilize isolated cell models that are amenable to genetic manipulation [13] and, therefore, have high scientific and experimental design potential but suffer from low clinical applicability since organ preservation injury is a complex mix of problems of multiple cell types in highly organized structures (organs). Conversely, studies that control for organ complexity, such as transplant models, are highly clinically relevant but suffer from low scientific and experimental design robustness, thus making mechanistic conclusions difficult. A hybrid approach that utilizes whole kidney storage and reperfusion with renal functional outcome parameters combined with genetic manipulation capability could potentially yield both translational relevancy and scientific and design robustness for solving mechanistic questions. We have developed an isolated perfused kidney (IPK) model of organ preservation injury in the mouse that accomplishes these two experimental attributes (translational relevancy 
and scientific robustness). The development and validation of this model is described herein.

\section{MATERIALS AND METHODS}

\section{Surgical Procedure}

Adult C57BL/6 mice were anesthetized and maintained in a surgical plane of anesthesia with Isoflurane (2-3\% with the balance being Oxygen). All experiments were first approved by the VCU Institutional Animal Care and Use Committee, which conforms to the NIH Guide and USDA laws and regulations concerning laboratory care and use of animals in biomedical research. A midline incision was performed and the intestines were wrapped in a wet sponge and retracted to expose the left kidney. The left ureter was mobilized from the kidney to the bladder and the right ureter was ligated and divided. The artery and vein supplying the left adrenal gland and the reproductive organs were ligated and divided. The abdominal aorta was carefully separated from the Vena Cava both superior and inferior to the left renal vessels. All visible lumbar vessels were ligated. The proximal aorta was surrounded with a 6-0 silk and two other silk ties were placed around the distal aorta. The Superior Mesenteric Artery (SMA) was then ligated and a drip of Lidocaine (1\%) was applied on the distal aorta, to relieve any vessel spasm. The distal aorta was tied followed by the proximal aorta and vena cava and the flush-out solutions was administered through a $1 \mathrm{ml}$ syringe with a $27 \mathrm{G}$ angled blunt needle inserted into the aorta between the ties. The solution was vented through a slit in the vena cava and about $1 \mathrm{ml}$ of cold heparinized (5 U/ml) University of Wisconsin (UW) solution or cold Eurocollins (EC) solution were slowly delivered to the left kidney. Following flush out, the aortic needle was replaced with a $26 \mathrm{G}$ Angiocath that was tied in place for later perfusion on the IPK. The kidney, aorta, remnant of the vena cava, ureter, and bladder were then removed en-block and placed in a specimen cup containing

\section{PLACEMENTS OF TIES}

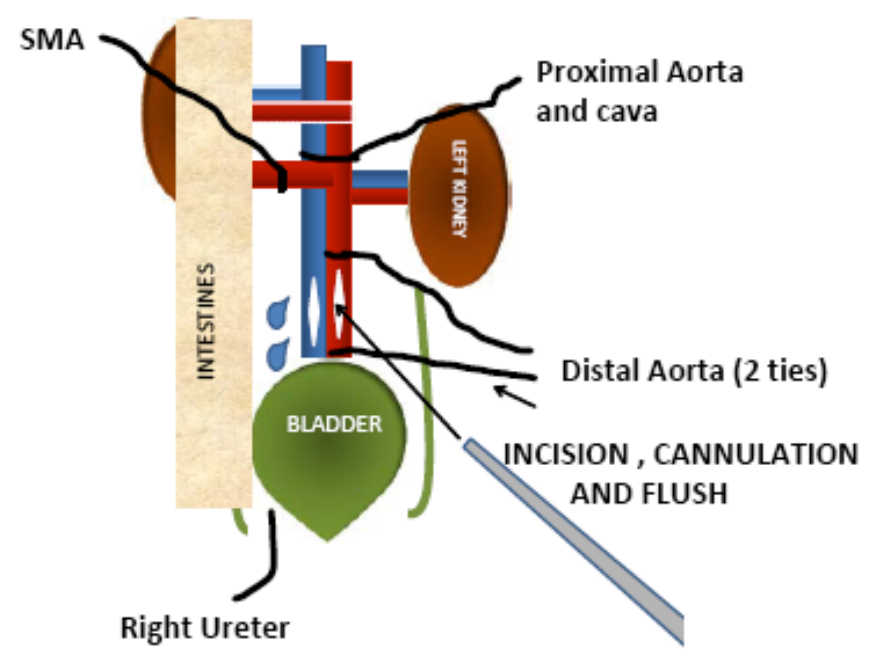

A cold UW or EC solution and stored in a refrigerator at $4{ }^{\circ} \mathrm{C}$ for 24 hours. In some experiments, the kidney was flushed with warm IPK perfusion buffer and the kidney was stored in a $37^{\circ} \mathrm{C}$ Water-bath for 1 hour to induce warm ischemia. A 7$\mathrm{cm}$ section of PE-10 tubing was inserted through the urethral opening of the bladder and secured with a silk tie. The contralateral kidney was removed and weighed. The surgical preparation is summarized in Fig. (1).

\section{IPK}

Fifty $\mathrm{ml}$ of IPK media $\left(\mathrm{KCl} 4 \mathrm{mM}, \mathrm{KH}_{2} \mathrm{PO}_{4} 1.2 \mathrm{mM}\right.$, $\mathrm{NaCl} 94.3 \mathrm{mM}, \mathrm{MgSO}_{4} 1.2 \mathrm{mM}, \mathrm{Na}_{2} \mathrm{HPO}_{4} 1 \mathrm{mM}$, Dextrose $5 \mathrm{mM}, \mathrm{NaHCO}_{3} 25 \mathrm{mM}$, Mannitol $20 \mathrm{mM}$, Butyrate $10 \mathrm{mM}$, LAlanine $2 \mathrm{mM}$, Creatinine $5 \mathrm{mg} \%$, Penicillin $0.10 \mathrm{mg} / \mathrm{L}$, Sigma 50x MEM Amino Acid solution 20ml/L, $\mathrm{CaCl}_{2}$ $1.3 \mathrm{mM}$, FITC-Inulin $0.1 \%$, and BSA $1 \%$ ) was re-circulated and oxygenated with $\mathrm{O}_{2} / \mathrm{CO}_{2}(95 \% / 5 \%)$ at $37^{\circ} \mathrm{C}$ through a tubing oxygenator. The oxygenator consisted of about 3 meters of silicone tubing (wall thickness $0.1 \mathrm{~mm}$, outside diameter, $1.6 \mathrm{~mm}$ ) coiled inside of a $125-\mathrm{ml}$ Erlenmeyer side-arm flask with the oxygen sweeping through the bottle at about $0.5 \mathrm{~L} / \mathrm{min}$ at a pressure of about 22 PSI (1.5 ATM). This maintained the media $\mathrm{PO}_{2}$ at about $500 \mathrm{~mm} \mathrm{Hg}$. Perfusate flow was regulated using the peristaltic pump's flow setting, to maintain a constant perfusion pressure of 100 $\pm 5 \mathrm{mmHg}$, which was monitored and continuously recorded on a data acquisition system (AD Instrument, Inc., Colorado Springs, CO).

\section{Protein Optimization Studies}

Preliminary studies were tested in 3 mouse kidneys to determine the effects of lowering the oncotic force of the IPK perfusate on urine formation. Historically, IPK studies have had very limited utility in studying renal preservation and ischemic injury since even small injuries to the kidney often lower the glomerular filtration rate and prevent urine

\section{FINAL PREPARARTION}

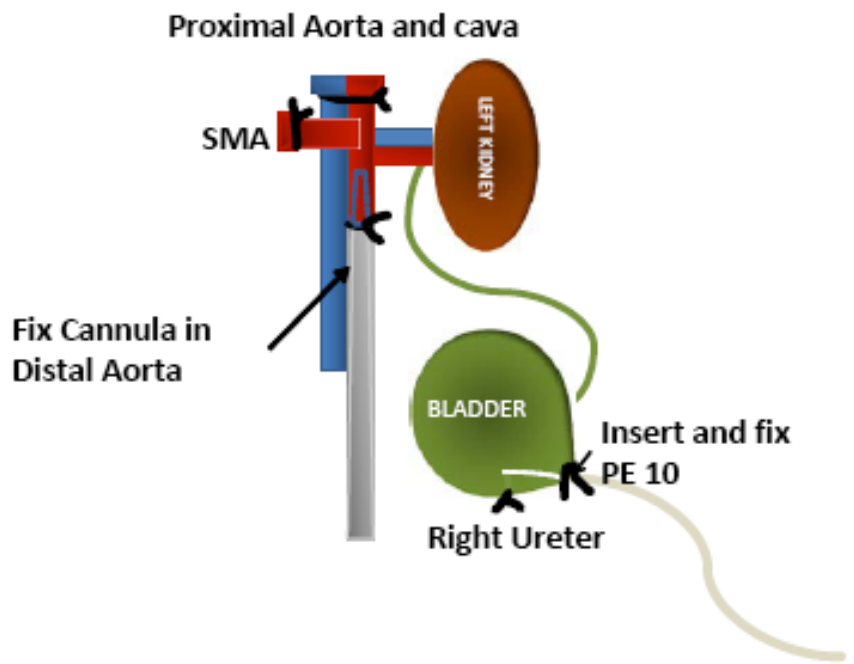

B

Fig. (1). Cartoon of the in-situ preparation and surgery for preparing a mouse kidney for cold preservation and reperfusion on the IPK, SMA $=$ Superior Mesenteric Artery. 
formation. Reperfusion of injured kidneys on the IPK that do not produce urine in the short 1-2 hour reperfusion period will fail to document preservation injury since many renal functional parameters are dependant on urine formation (GFR, urine production rate per se, fractional reabsorption of electrolytes, protein excretion, tubular function, etc.). Therefore, to possibly mitigate this problem, we hypothesized that simply reducing the oncotic force in the glomerular capillary during IPK reperfusion would shift the Starling forces sufficient to allow urine formation in amounts necessary to quantitate renal function and to document preservation injury in compromised kidneys. To that end, we studied urine formation in normal mouse kidneys subjected to 3 concentrations of oncotic force by using 3 different albumin concentrations in the perfusate $(5,3$, and $1 \%)$. We then used these results to adjust the oncotic strength of the IPK perfusate for our experimental studies.

\section{Equilibration Period (30 Minutes)}

After the first 30-minute equilibration period, a baseline perfusate sample was collected from the arterial inflow and venous outflow sides of the circulation for measurement of $\mathrm{PO}_{2}$ on a Radiometer 800 blood gas analyzer. Oxygen consumption $(\mathrm{ml} / \mathrm{min} / \mathrm{g})$ was calculated as the product of the perfusate flow and the arterio-venous oxygen content difference $\left(\mathrm{A}-\mathrm{V} \mathrm{O}_{2}\right)$. The urine outflow from the PE-10 cannula was directed into a pre-weighed micro-centrifuge tube for urine collection.

\section{Experimental Period (60 Minutes)}

After the equilibration period, the kidney was allowed to perfuse for a $60 \mathrm{~min}$ test period. During this time, perfusate flow, vascular resistance, urine production rate, urinary protein excretion, GFR, $\mathrm{VO}_{2}$, and $\mathrm{LDH}$ release were measured. GFR was estimated by the clearance of either creatinine or inulin (FITC-labeled inulin). After the 60-minute period, the kidney was weighed before and after 72 hours of oven drying $\left(60^{\circ} \mathrm{C}\right)$ to calculate total tissue water (TTW, $\mathrm{Kg} \mathrm{H}_{2} \mathrm{O}$ / $\mathrm{kg}$ wet weight).

\section{ANALYTICAL}

\section{Creatine Clearance}

Creatinine in urine and perfusate was estimated by a spectrophotometric picric acid assay (modified Jaffe reaction). Briefly, a working stock of $0.2 \mathrm{~N} \mathrm{NaOH}, 0.5 \mathrm{~N}$ EDTA, and $2.1 \mathrm{~g} / \mathrm{l}$ picric acid was prepared fresh. The reaction was started by adding the working picric acid stock to the perfusate and urine samples (10-20ul). After incubation for $30 \mathrm{~min}$ at room temperature, 100ul of the samples were transferred to a 96 well plate and read in a plate reader (Biotek, Winooski, VT, Model ELx800) at $490 \mathrm{nM}$ and the unknown sample values were extrapolated from a standard curve run under the same conditions using authentic creatinine dilutions. The sensitivity of the assay was about 1.0 $\mathrm{mg} / \mathrm{dl}$ creatinine so we chose to add $5 \mathrm{mg} / \mathrm{dl}$ creatinine to the IPK perfusate to ensure enough mass for detection in the assay. Creatinine clearance was computed in the usual way as the product of the ratio of creatinine in the urine to that in the perfusate and the urine flow rate.

\section{Inulin}

The concentration of FITC-Inulin in the perfusate and urine samples was determined as previously described [14] by adding $40 \mu \mathrm{l}$ of the samples (buffered with $10 \mu \mathrm{l} 500 \mathrm{mM}$ HEPES) to wells of a 96-well plate and reading them on a fluorescence plate reader (Biotek, Winooski, VT, Model FLx800)) with an excitation wavelength of $485 \mathrm{nM}$ and an emission wavelength of $520 \mathrm{nM}$. Inulin clearance was then calculated in the same way as creatinine clearance and both served to estimate the glomerular filtration rate (GFR).

\section{Protein Assay}

Urinary protein excretion was determined by assaying protein in the urine, diluted $1 / 10$ using the BCA technique and a kit from Pierce (Thermo Scientific, Rockford, IL). Samples were reacted in a 96-well plate and read at $630 \mathrm{nM}$ in a plate reader (Biotek, Winooski, VT, Model ELx800). The sensitivity of this assay was $60 \mu \mathrm{g}$ protein $/ \mathrm{ml}$.

\section{Lactate Dehydrogenase (LDH)}

Renal injury during storage and reperfusion on the IPK was also assessed by measuring the release of intracellular $\mathrm{LDH}$ into the perfusate after $90 \mathrm{~min}$ of recirculated reperfusion. Samples of the perfusate were assayed for LDH using a previously described spectrophotometric assay [15].

\section{Total Tissue Water (TTW)}

The TTW of preserved organs is used to asses preservation injury since a significant mechanism of preservation injury arises from the failure of the cell to control its volume during cold storage and after reperfusion [11,16]. Cell swelling is a lethal problem in organ preservation and it can be grossly quantitated by measuring the accumulation of tissue water after preservation by weighing tissue samples of the kidneys before and after oven drying and expressing the water content as the volume of water per mg dry weight.

\section{Experimental Design}

Mouse kidneys were harvested and randomly assigned to one of the following (9) groups;

\section{Fresh Controls}

These kidneys were immediately flushed with cold IPK media before being removed, to prevent any warm ischemia and had no significant cold ischemia ( $<30 \mathrm{~min})$, then perfused on the IPK for $90 \mathrm{~min}$.

\section{UW 24 Hrs}

These kidneys were harvested, flushed with UW solution, cold stored for 24 hours, and reperfused on the IPK for 90 $\min$.

\section{UW $48 \mathrm{Hrs}$}

These kidneys were harvested, flushed with UW solution, cold stored for 48 hours, and reperfused on the IPK for 90 $\min$.

\section{UW 72 Hrs}

These kidneys were harvested, flushed with UW solution, cold stored for 72 hours, and reperfused on the IPK for 90 $\min$. 


\section{EC $72 \mathrm{Hrs}$}

These kidneys were harvested, flushed with Eurocollins (EC) solution, cold stored for 72 hours, and reperfused on the IPK for $90 \mathrm{~min}$.

\section{WI $60 \mathrm{Min}$}

These kidneys were flushed with warm IPK media (37$38^{\circ} \mathrm{C}$ ) and the temperature was maintained at $37^{\circ} \mathrm{C}$ for 60 min, using a water-bath, followed by reperfusion on the IPK for $90 \mathrm{~min}$

\section{WI 90 Min}

These kidneys were flushed with warm IPK media (37$38^{\circ} \mathrm{C}$ ) and the temperature was maintained at $37^{\circ} \mathrm{C}$ for 90 $\mathrm{min}$, using a water-bath, followed by reperfusion on the IPK for $90 \mathrm{~min}$.

\section{WI $30 \mathrm{Min} / \mathrm{CS}$}

These kidneys were flushed with warm IPK media (37$38^{\circ} \mathrm{C}$ ) and the temperature was maintained at $37^{\circ} \mathrm{C}$ for 30 min, using a water-bath. After the WI period, the kidneys were flushed with cold UW solution and cold stored in the same for $24 \mathrm{hrs}$, followed by reperfusion on the IPK for 90 min.

\section{WI $60 \mathrm{Min} / \mathrm{CS}$}

These kidneys were flushed with warm IPK media (37$38^{\circ} \mathrm{C}$ ) and the temperature was maintained at $37^{\circ} \mathrm{C}$ for 30 min, using a water-bath. After the WI period, the kidneys were flushed with cold UW solution and cold stored in the same for $24 \mathrm{hrs}$ followed by reperfusion on the IPK for 90 $\min$.

\section{Statistical Analysis}

The endpoints of the study were the renal functional parameters derived during or after the IPK reperfusion period. A Power test was used to determine the approximate sample size for each experimental group such that a $30 \%$ change in perfusate flow rate could be detected with a power of 0.8 at an alpha of 0.05 . The sample size was determined to be about 8 per group. Data were expressed as mean \pm SD and were analyzed by one way ANOVA and Bonferroni's post test. A P value of 0.05 was considered statistically significant.

\section{RESULTS}

The effect of perfusate protein concentration on mouse kidney urine production is shown in Fig. (2). In normal mouse kidneys on the IPK, urine production increased 3 fold and 4 fold as the protein (BSA) concentration in the perfusate was reduced to $3 \%$ and $1 \%$, respectively. A physiologically normal value of $5 \%$ was used as the baseline. Therefore, a BSA concentration of $1 \%$ was used in the perfusate hereafter in all of the experimental groups since it maximized urine production and had little or no effect on total tissue water (TTW) in normal mouse kidneys (data not shown).

Various renal functional parameters from mouse kidneys subjected to different levels of preservation injury are shown in Fig. (3). Perfusate flow, oxygen uptake $\left(\mathrm{VO}_{2}\right)$, and urine production were all significantly reduced as the severity of preservation injury increased. The converse relationship was seen with vascular resistance. Specifically, as the length of cold preservation in any given preservation solution increased or as the quality of preservation solution decreased (UW vs. Eurocollins), renal function declined. Similar relationships are shown in Fig. (4) for protein excretion in the urine, creatinine clearance (GFR), LDH release by the kidney during reperfusion, and tissue water accumulation.

Another significant risk factor for preservation injury is the presence of prior warm ischemia before hypothermic preservation. Table 1 shows the effects of graded warm

Table 1. Effect of Warm Ischemia Times (WIT), alone or in Combination with 24hrs Cold Storage (CS) in UW-Solution, on Parameters of Renal Function and Preservation Injury

\begin{tabular}{|c|c|c|c|c|}
\hline $\begin{array}{l}\text { WIT (min)/ } \\
\text { CS (UW) }\end{array}$ & $\begin{array}{l}\text { Perfusate flow } \\
(\mathrm{ml} / \mathrm{min} / \mathrm{g})\end{array}$ & $\begin{array}{c}\mathrm{RVR} \\
(\mathrm{mmHg} / \mathrm{ml} / \mathrm{min} / \mathrm{g})\end{array}$ & $\begin{array}{c}\mathrm{VO}_{2} \\
(\mathrm{ml} / \mathrm{min} / 100 \mathrm{~g})\end{array}$ & $\begin{array}{c}\text { Urine Flow } \\
(\mu \mathrm{l} / \mathrm{min} / \mathrm{g})\end{array}$ \\
\hline $0 \mathrm{~h}$ (Control) & $26.9 \pm 4.4$ & $1.7 \pm 0.5$ & $1.75 \pm 0.28$ & $193 \pm 29$ \\
\hline WI $60 \mathrm{~min}$ & $14.8 \pm 2.8^{*}$ & $5.6 \pm 2.1$ & $0.6 \pm 0.1^{*}$ & $11.6 \pm 3.8^{*}$ \\
\hline WI 90min & $6.3 \pm 0.9^{*}$ & $22.3 \pm 4.8^{*}$ & $0.5 \pm 0.1^{*}$ & $18.7 \pm 3.2 *$ \\
\hline WI 30/CS & $17.1 \pm 2.0^{*}$ & $1.9 \pm 0.4$ & $0.7 \pm 0.2^{*}$ & $43.0 \pm 11.2 *$ \\
\hline WI $60 / \mathrm{CS}$ & $9.8 \pm 2.6^{*}$ & $26.1 \pm 11.5^{* \#}$ & $0.5 \pm 0.1^{*}$ & $20.3 \pm 9.7 *$ \\
\hline
\end{tabular}

\begin{tabular}{|c|c|c|c|c|}
\hline $\begin{array}{c}\text { WIT (min)/ } \\
\text { CS (UW) }\end{array}$ & $\begin{array}{c}\text { GFR } \\
(\boldsymbol{\mu l} / \mathbf{m i n} / \boldsymbol{g})\end{array}$ & $\begin{array}{c}\text { Protein excretion } \\
(\boldsymbol{\mu} \boldsymbol{g} / \boldsymbol{g})\end{array}$ & $\begin{array}{c}\text { LDH } \\
(\boldsymbol{U} / \mathbf{L} / \boldsymbol{g})\end{array}$ & $\begin{array}{c}\text { TTW } \\
\left(\boldsymbol{m g} \boldsymbol{H}_{2} \boldsymbol{O} / \boldsymbol{m g} \mathbf{d r y} \boldsymbol{w e i g h t}\right)\end{array}$ \\
\hline \hline 0 h (Control) & $632 \pm 142$ & $1.4 \pm 0.5$ & $2592 \pm 489$ & $3.37 \pm 0.28$ \\
\hline WI 60min & $17.9 \pm 6.7^{*}$ & $511.6 \pm 89.5^{*}$ & $4211 \pm 1101$ & $4.11 \pm 0.19$ \\
\hline WI 90min & $18.8 \pm 2.2^{*}$ & $433.5 \pm 73.0^{*}$ & $6375 \pm 579^{*}$ & $5.08 \pm 0.13^{*}$ \\
\hline WI 30/CS & $54 \pm 13$ & $135 \pm 63^{*}$ & $4431 \pm 465$ & $4.03 \pm 0.21$ \\
\hline WI 60/CS & $22 \pm 13^{*}$ & $492 \pm 91^{*}$ & $6682 \pm 937^{*}$ & $5.21 \pm 0.36^{*}$ \\
\hline
\end{tabular}


ischemia times per se and in combination with cold storage on renal graft function after reperfusion on the IPK. Gene-

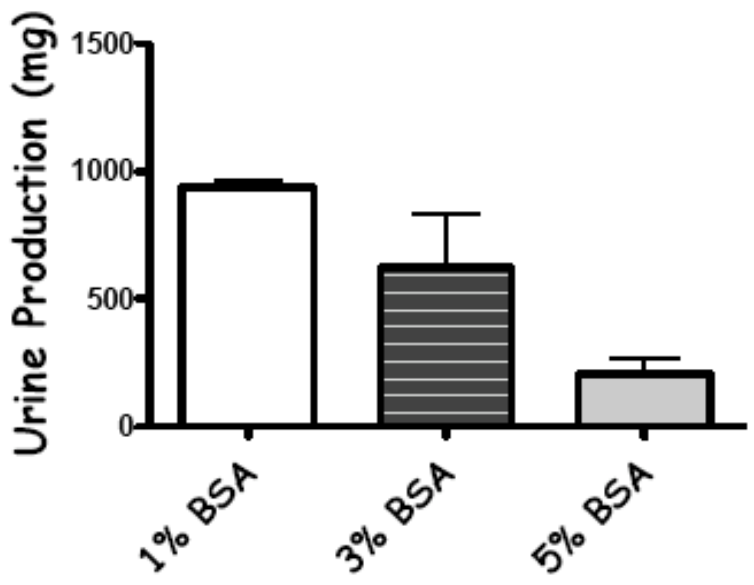

Fig. (2). The effects of changing the concentration of bovine serum albumin (BSA) on urine production in mouse kidneys (fresh nonstored). Physiological concentrations of BSA in the perfusate (5\%) severely limit urine formation in fresh kidneys and often prevent it from occurring at all in kidneys with preservation in jury. This prevents the determination of renal function that is based on urine formation (GFR, proteinuria, renal handling of electrolytes, etc.). Values are mean $\pm \mathrm{SD}, \mathrm{n}=3$ mice.
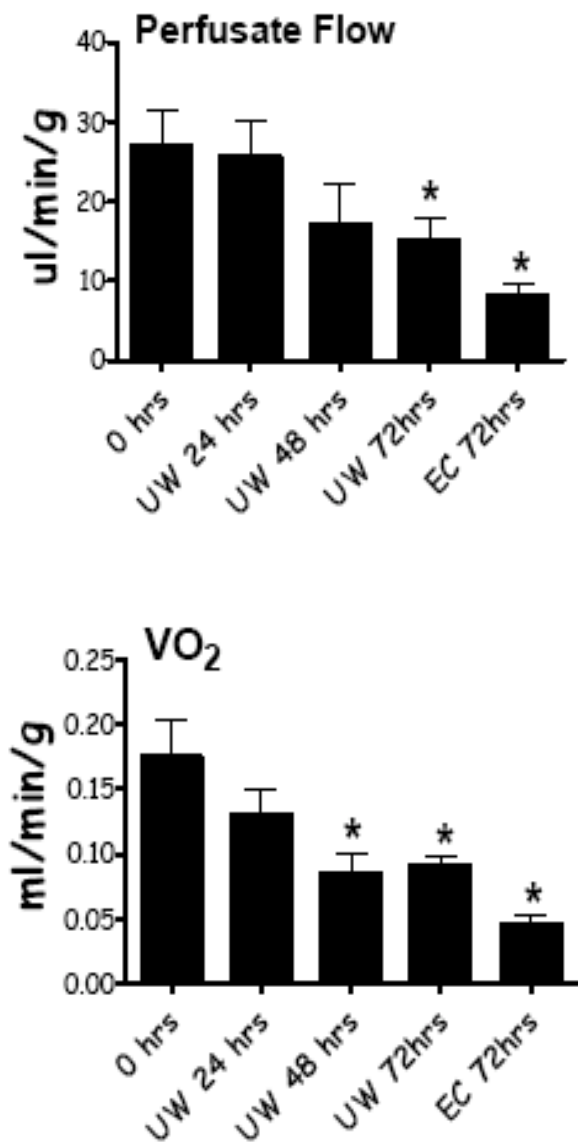

rally, warm ischemia caused renal function to decline, sometimes dose dependently. Similarly, the combination of warm ischemia $(60 \mathrm{~min})$ with cold storage $(24 \mathrm{hrs}$ in UW) produced more preservation injury, as indexed by some measured parameters, compared to just warm ischemia alone (60 minutes).

Finally, the utility of estimating GFR in this model using creatinine clearance was determined. Mouse kidney GFR was assessed simultaneously using creatinine and inulin clearance and is shown in Fig. (5). Absolute GFR values segregated into two relative populations; higher values observed in normal control kidneys without preservation or ischemic injury (Control Data) and significantly lower GFR values observed in the experimental kidneys subjected to preservation injury (Experimental Data). Using inulin clearance as the gold standard, we were able to determine that GFR estimated by creatinine clearance in this model comes very close to identity with GFR estimated by inulin clearance when the true GFR (inulin clearance) is relatively low (below $200 \mu \mathrm{l} / \mathrm{min}$ ). These values occurred in the injured experimental kidneys. However, the relationship between creatinine and inulin clearance changed at the higher GFR rates such that creatinine clearance over-estimated true GFR (inulin clearance). However, in both high and low GFR groups, the correlation between the two methods was very strong $\left(\mathrm{R}^{2}=0.95\right.$ in the higher GFR group and 0.85 in the lower GFR group, $\mathrm{P}<0.0001$ ).
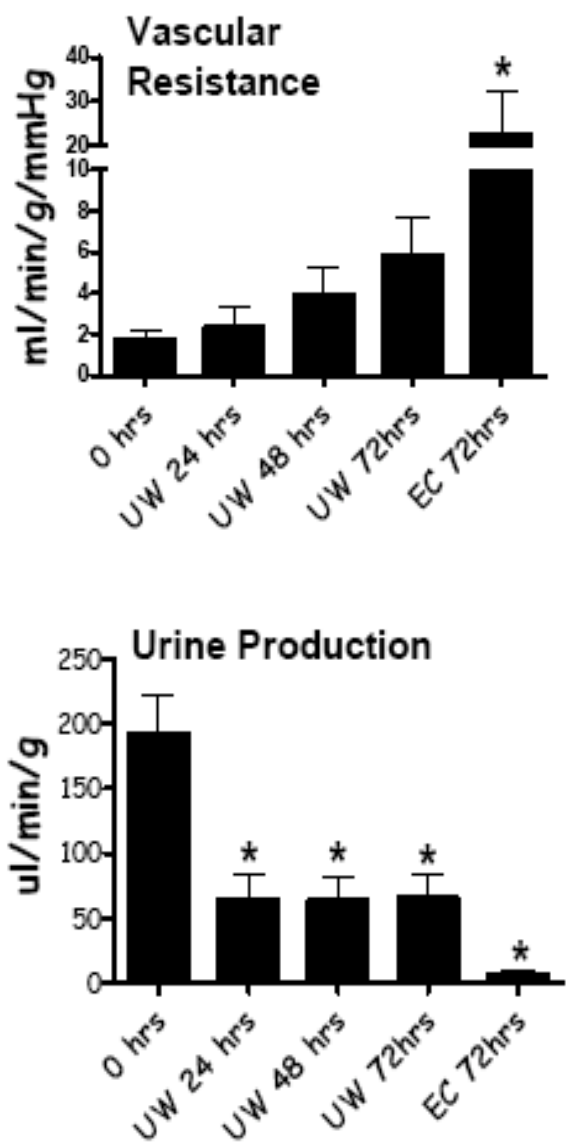

Fig. (3). Renal functional read outs from IPK studies using fresh kidneys, kidneys stored in UW solution for 24, 48, and 72 hrs, and in kidneys cold stored with Eurocollins solution with 72 hrs. Reperfusion times were 60 minutes. Values are mean $\pm \mathrm{SD}, \mathrm{n}=8 \mathrm{mice}$ per group. * $\mathrm{P}<0.05$ relative to $0 \mathrm{hrs}$. 

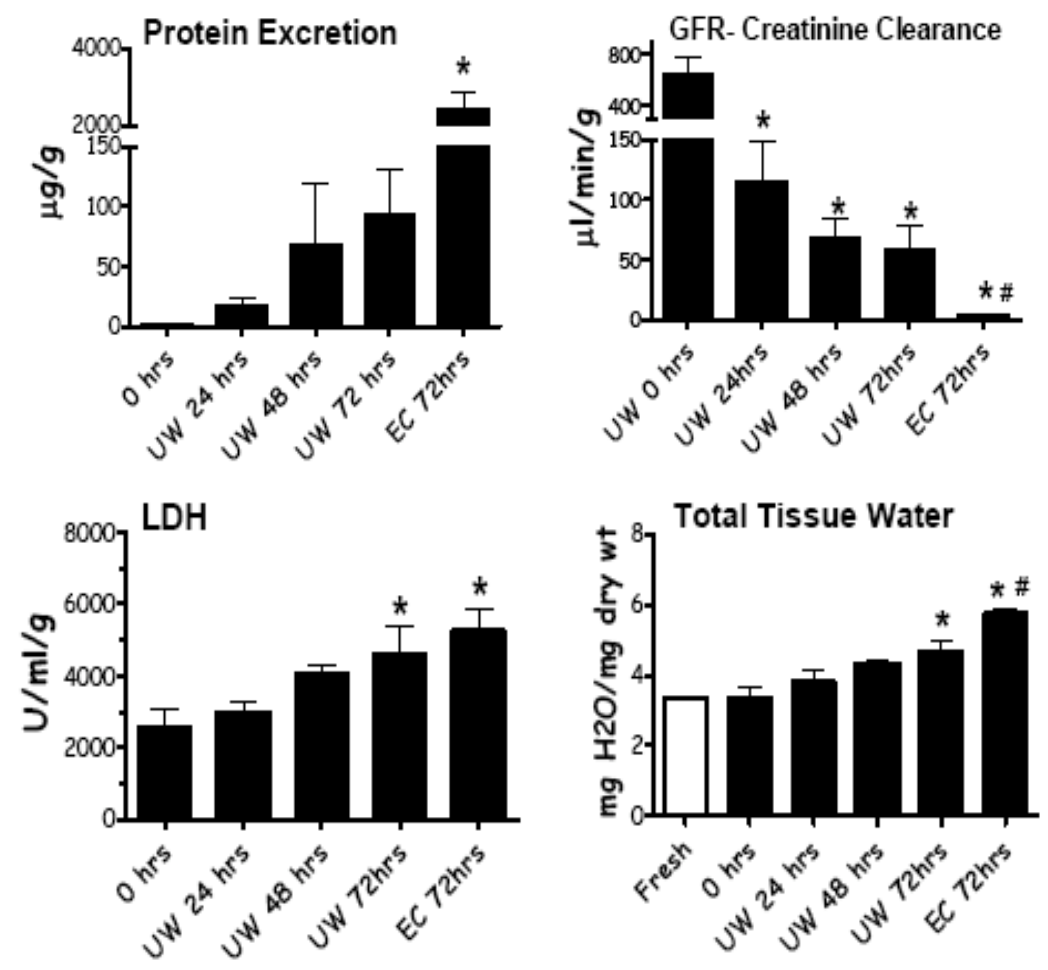

Fig. (4). Renal functional read outs from IPK studies using fresh kidneys, kidneys stored in UW solution for 24,48 , and 72 hrs, and in kidneys cold stored with Eurocollins solution with 72 hrs. Reperfusion times were 60 minutes. Values are mean \pm SD, $n=8$ mice per group. * $\mathrm{P}<0.05$ relative to $0 \mathrm{hrs}$, \# $\mathrm{P}<0.05$ relative to UW $72 \mathrm{hrs}$.
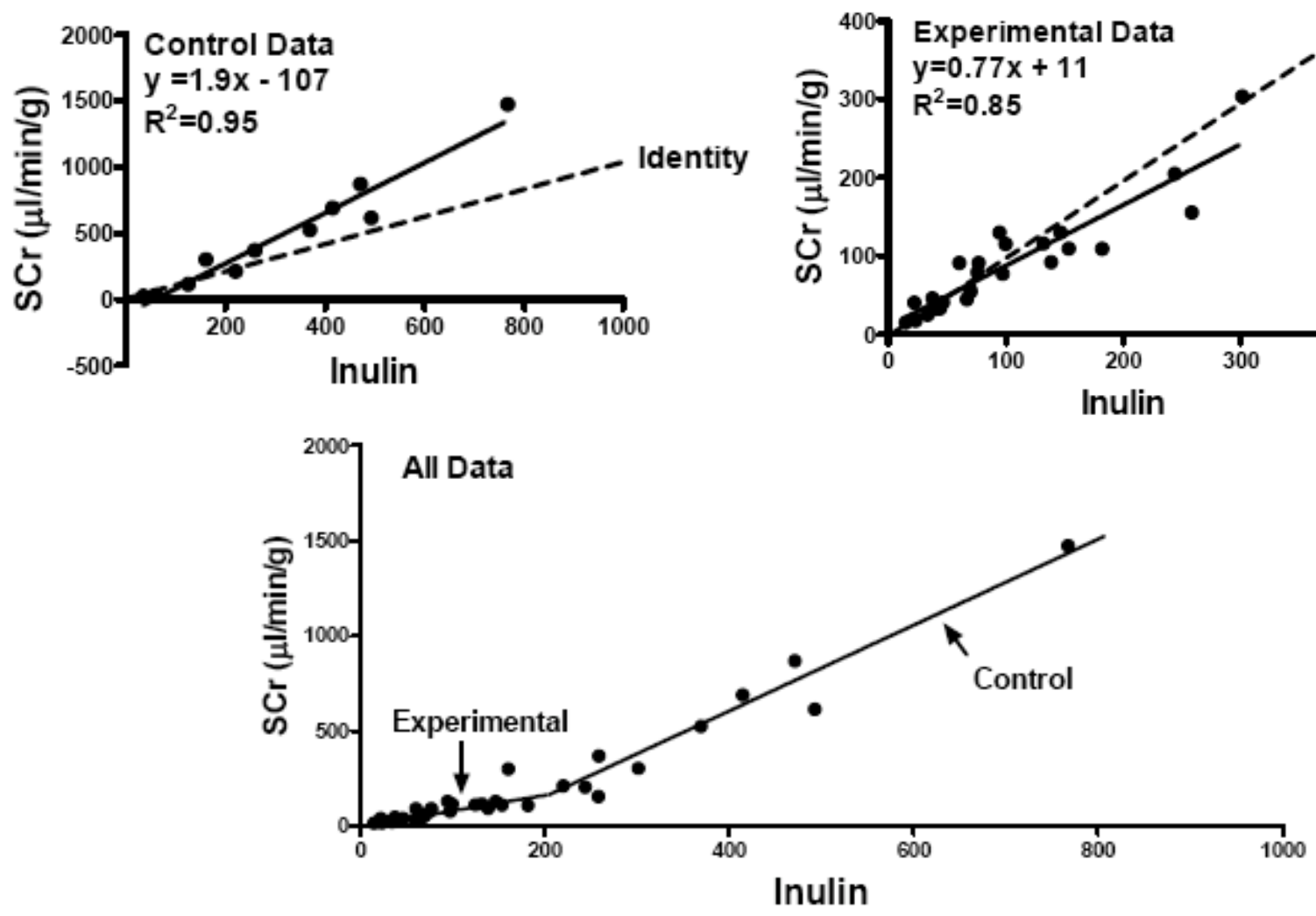

Fig. (5). Correlations between inulin clearance and creatinine clearance in mouse kidneys on the IPK. The upper panel shows the relationship in healthy fresh kidneys with no preservation injury and high GFR. The middle panel is from the test groups with injury and lower GFR values. The bottom panel shows all values together. 


\section{DISCUSSION}

The purpose of this study was to develop, refine, and test an IPK system using mouse kidneys that were suitable for studying organ preservation injury. The mouse IPK model is a good compromise between whole kidney transplant studies that provide functional data for all integrated tissues and cells in the kidney with the scientific robustness of an epithelial cell culture model. Short term reperfusion of the whole organ after preservation produce clinically and physiologically relevant read outs after reperfusion that may be clinically useful while the genetic manipulation potential of the mouse provide appealing experimental design characteristics to test mechanisms and causations. However, both the short term nature and the acellularity of the reperfusion in the IPK model present some limitations to its usefulness.

A significant limitation of using the IPK model to study renal injury such as organ preservation is the resolution of the model during injury. Specifically, most typical IPK designs are sensitive to injury induced by preservation ischemia, which results in loss of filtration and urine output. Even moderate amounts of injury, which are known to be clinically insignificant, can produce a loss of filtration and urine formation that prevents the determination of renal functional read outs in the IPK. It was hypothesized that physiological amounts of colloid in the perfusates (5\% BSA) may contribute to this problem and simply reducing the starling forces in the glomerular capillary to favor filtration might be adequate to correct it. When the BSA concentration was reduced to $1-3 \%$ in this model, urine formation was markedly increased, even in the face of severe preservation injury. Presumably, this occurred by promoting filtration in the glomerulus by reducing the oncotic force in the glomerular capillary. This now allows for the measurement of a vast array of functional parameters after reperfusion, which serves to quantitate the degree and even location of preservation injury. The low degree of functional resolution in past IPK models severely limited its utility for studying organ preservation injury. However, this simple modification has corrected that limitation.

The baseline values in the normal control kidneys in this study are in general agreement with Rahgozar's study in the mouse IPK [17]. They reported a slight improvement in renal function with increasing concentrations of BSA from 4 to $5.5 \%$. The addition of $1 \%$ washed RBCs to the perfusate further enhanced renal function, suggesting the need for improved oxygen delivery during reperfusion. Their preparations were sensitive to reperfusion time-dependent degradation in renal function like in this study, so the utility of these assays past $2 \mathrm{hrs}$ is limited. Despite these differences, we were able to demonstrate high predictive resolution in the degree of organ preservation injury using the mouse IPK. For example, increasing cold storage time in UW solution produced predictable time dependant drops in renal functional performance as did switching from UW solution (a good preservative) to Eurocollins solution (a poorer preservative). Finally, addition of dose dependent amounts of prior warm ischemia to the kidney before cold storage produced the predictable changes in renal function immediately after reperfusion. All of these changes in the mouse IPK have been demonstrated in prior studies using clinically relevant transplant models in large animal kidney transplant experiments [15,18-20], which indicate that the mouse IPK may be a simple surrogate for more complicated pre-clinical kidney transplant studies. The additional benefit of the mouse IPK is that now genetic alterations in the whole kidney, through homologous recombination technology, can be performed. This will allow for the precise testing of mechanisms of organ preservation injury by targeted gene deletion, mutation, or addition.

Dog kidney auto-transplant studies by Ploeg [20] demonstrated both solution and storage time dependent changes in renal function. However, this predictive power was lost when the kidneys were reperfused on the IPK. Specifically, the transplanted kidney function at transplantation correlated with the degree of cold storage and the type of storage solution that was used but the functional readouts from the contralateral kidneys subjected to the same conditions did not correlate well when they were reperfused on the IPK. Therefore, mouse kidneys perfused on the IPK after preservation injury are more predictive of the actual transplant outcomes than are dog kidneys perfused on the IPK. This seems counterintuitive since the dog kidney transplant model is a gold standard for predicting human renal preservation injury [20-22].

Renal preservation injury is a complex and multifactorial process. One important factor in determining post-transplant preservation injury in kidneys is the degree and quality of the cellular inflammatory response to tissue injury caused by the storage ischemia and the storage hypothermia. The IPK model will not detect this mechanism of injury since the perfusion media is an acellular crystalloid and the reperfusion time is not conducive to cellular inflammation even if the cells were present. The IPK in the mouse as described in this study only runs for about 90 minutes after reperfusion. Longer times result in time-dependent declines in renal functional and biochemical end points. These are likely due to a slow progressive ischemia since most IPK systems fail to deliver the oxygen that is required to meet the demands of the tissue at $37^{\circ} \mathrm{C}$. The addition of whole blood components back to the IPK perfusate is not a reasonable approach in the mouse IPK since too many mice would be required to obtain enough donor whole blood. One solution that has been explored in the lab is to perform kidney transplantation into a syngeneic recipient after preservation and allow the graft to undergo whole blood reperfusion for 24 or 48 hours. Then the transplanted kidney is removed and placed on the mouse IPK device to measure precise renal function and to evaluate preservation injury. This can be done successfully and the resulting preservation injury includes the cellular inflammatory component that occurs after reperfusion, which cannot be determined by using conventional reperfusion with crystalloids alone.

In conclusion, this study has refined a technique for measuring renal preservation injury (and other forms of renal injury) in a mouse IPK model. The technique not only predicts known changes associated with hypothermic renal preservation injury but also provides a genetic platform by which molecular mechanisms of injury can be tested. 


\section{ACKNOWLEDGEMENT}

Susanne Lindell, Natascha Williams, Ilia Brusilovsky, and Martin Mangino conducted the study, analyzed the data, and wrote the paper.

\section{FINANCIAL SUPPORT}

This work was funded by the Medical College of Virginia Foundation.

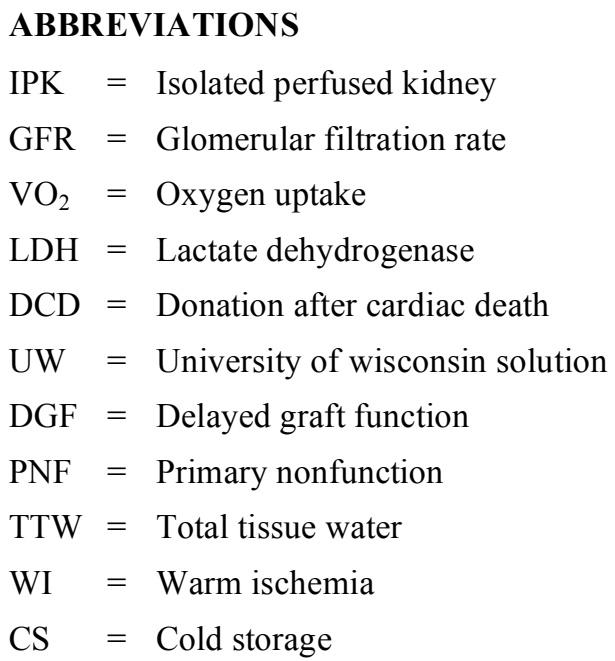

\section{REFERENCE}

[1] United Network for Organ Sharing. OPTN National Report. 2009. Ref Type: Report.

[2] Kyllonen LE, Salmela KT, Eklund BH, et al. Long-term results of 1047 cadaveric kidney transplantations with special emphasis on initial graft function and rejection. Transpl Int 2000; 13: 122-8.

[3] Tandon V, Botha JF, Banks J, Pontin AR, Pascoe MD, Kahn D. A tale of two kidneys--how long can a kidney transplant wait? Clin Transplant 2000; 14: 189-92.

[4] Peters TG, Shaver TR, Ames JE, et al. Cold ischemia and outcome in 17,937 cadaveric kidney transplants. Transplant 1995; 59: 191-6.

[5] Pfaff WW, Howard RJ, Patton PR, Adams VR, Rosen CB, Reed AI. Delayed graft function after renal transplantation. Transplant 1998; 65: 219-23.

[6] Troppmann C, Gillingham KJ, Benedetti E, et al. Delayed graft function, acute rejection, and outcome after cadaver renal transplantation. The multivariate analysis. Transplant 1995; 59: 962-8.

[7] Moers C, Smits JM, Maathuis MH, et al. Machine perfusion or cold storage in deceased-donor kidney transplantation. N Engl J Med 2009; 360: 7-19.

[8] Stratta RJ, Moore PS, Farney AC, et al. Influence of pulsatile perfusion preservation on outcomes in kidney transplantation from expanded criteria donors. J Am Coll Surg 2007; 204: 873-82.

[9] Southard JH, Beltzer FO. Principles of Organ Preservation Part I. Surgical Rounds 1993; 353-60.

[10] Southard JH, Beltzer FO. Principles of Organ Preservation Part II. Surgical Rounds 1993; 443-8.

[11] Southard JH, Belzer FO. Control of canine kidney cortex slice volume and ion distribution at hypothermia by impermeable anions. Cryobiol 1980; 17: 540-8.

[12] Southard JH, Lutz MF, Ametani MS, Belzer FO. Stimulation of ATP synthesis in hypothermically perfused dog kidneys by adenosine and PO4. Cryobiology 1984; 21: 13-19.

[13] Tian T, Lindell SL, Henderson SC, Mangino MJ. Protective effects of ezrin on cold storage preservation injury in the pig kidney proximal tubular epithelial cell line (LLC-PK1). Transplant 2009; 87: 1488-96.

[14] Qi Z, Whitt I, Mehta A, et al. Serial determination of glomerular filtration rate in conscious mice using FITC-inulin clearance. Am J Physiol Renal Physiol 2004; 286: F590-F6.

[15] Mangino MJ, Ametani M, Szabo C, Southard JH. Poly(ADPribose) polymerase and renal hypothermic preservation injury. Am J Physiol Renal Physiol 2004; 286: F838-F47.

[16] Southard JH, Beltzer FO. Principles of Organ Preservation Part I. Surgical Rounds 1993; 353-60.

[17] Rahgozar M, Guan Z, Matthias A, Gobe GC, Endre ZH Angiotensin II facilitates autoregulation in the perfused mouse kidney: An optimized in vitro model for assessment of renal vascular and tubular function. Nephrology (Carlton) 2004; 9: 28896.

[18] Lindell SL, Compagnon P, Mangino MJ, Southard JH. UW solution for hypothermic machine perfusion of warm ischemic kidneys. Transplant 2005; 79: 1358-61.

[19] Mangino MJ, Kosieradzki M, Gilligan B, Woo H, Southard JH. The effects of donor brain death on renal function and arachidonic acid metabolism in a large animal model of hypothermic preservation injury. Transplant 2003; 75: 1640-7.

[20] Ploeg RJ, Goossens D, Mcanulty JF, Southard JH, Belzer FO. Successful 72-hour cold storage of dog kidneys with UW solution. Transplant 1988; 46: 191-6.

[21] Hoffmann RM, Stratta RJ, D'Alessandro AM, et al. Combined cold storage-perfusion preservation with a new synthetic perfusate. Transplantation 1989; 47: 32-7.

[22] Mcanulty JF, Ploeg RJ, Southard JH, Belzer FO. Successful fiveday perfusion preservation of the canine kidney. Transplant 1989; 47: 37-41.

\section{(C) Lindell et al.; Licensee Bentham Open.}

This is an open access article licensed under the terms of the Creative Commons Attribution Non-Commercial License (http://creativecommons.org/ licenses/by-nc/3.0/), which permits unrestricted, non-commercial use, distribution and reproduction in any medium, provided the work is properly cited. 